\title{
ALGUMAS CARACTERÍSTICAS DAS POLÍTICAS DE ACREDITAÇÃO E AVALIAÇÃO DA EDUCAÇÃO SUPERIOR DA COLÔMBIA: INTERFACES COM O BRASIL ${ }^{1}$
}

\author{
Vicente de Paula Almeida Júnior* \\ Afrânio Mendes CATAni**
}

Recebido em: 11 de maio de 2009

Aprovado em: 22 de junho de 2009

*Bolsista de Pós-Doutorado Júnior do CNPq. Membro do Grupo de Pesquisa em Educação Superior Universidade de Sorocaba, UNISO.E-mails: vicentejunior@usp.br; vicentealmeidajunior@yahoo.com.br ** Prof. Dr. no Departamento de Administração Escolar e Economia da Educação, Faculdade de Educação, USP. Pesquisador do CNPq. E-mail: amcatani@usp.br

Resumo: Apresentamos, neste artigo, algumas características das políticas de acreditação e de avaliação da educação superior da Colômbia e as suas interfaces com o Brasil. Nosso intuito geral é o de contribuir para o debate referente à reflexão sobre o papel dessas políticas no desenvolvimento dos sistemas de educação superior na região. Especificamente, nos propomos a levantar, comparando com a realidade brasileira, alguns pontos relevantes da Colômbia em relação às múltiplas complexidades nas quais estão inscritos, na atualidade, os temas da acreditação e da avaliação. De modo geral, segundo os estudos parcialmente construídos aqui, os mecanismos de acreditação e avaliação estão na lista de prioridades da agenda governamental e acadêmica tanto na Colômbia quanto no Brasil. Nesse quadro, eles representam o esforço de cooperação internacional na região, porém com dupla finalidade e não isento de contradições: de um lado, para defender os interesses nacionais, dando ênfase na educação superior como bem público sujeito às ações e estratégias do Estado e não do mercado e, de outro, para ampliar a mobilidade estudantil e docente num quadro crescente de mudanças sociais, econômicas e culturais, garantindo e assegurando a qualidade da formação educacional e científica das pessoas.

Palavras-chave: Processo de Bolonha. Educação superior. Acreditação. Avaliação. Políticas educacionais.

\section{CHARACTERISTICS OF ACCREDITATION AND EVALUATION POLICIES IN COLUMBIAN HIGHER EDUCATION: INTERFACES WITH BRAZIL}

\begin{abstract}
We present in this article some characteristics of accreditation and evaluation policies for higher education in Colombia and their interfaces with Brazil. Our overall aim is to contribute to the debate on the role of policies in the development of higher education systems in the region. Specifically, we propose to raise, in comparison with the Brazilian reality, some relevant points of Colombia relative to the multiple complexities in which the issues of accreditation and evaluation are presently registered. In general, based on the studies partially constructed here, the mechanisms of accreditation and evaluation are in the list of priorities of the governmental and academic agenda, both in Colombia and in Brazil. In this framework, they represent the effort of international cooperation in the region, but with dual purpose and not without contradictions: on one hand to defend national interests, with emphasis on education as a public subject to the actions and strategies of the state and not the market, and on the other hand, to increase student and teacher mobility in a growing number of social, economic and cultural changes, guaranteeing and ensuring the quality of education.
\end{abstract}

Key words: Bologna process. Higher education. Accreditation. Evaluation. Educational policies.

1 O presente artigo é parte de um estudo em desenvolvimento junto ao Departamento de Administração Escolar e Economia da Educação da Faculdade de Educação da Universidade de São Paulo (USP), em nível de pós-doutorado, sob a supervisão do Professor Doutor Afrânio Mendes Catani e a colaboração do Prof. Dr. José Dias Sobrinho - Universidade de Sorocaba, UNISO. 


\section{Introdução}

Apresentamos, neste artigo, algumas características das políticas de acreditação e de avaliação da educação superior da Colômbia e as suas interfaces com o Brasil. Ao apresentá-las, nosso intuito geral é o de contribuir para o debate referente à reflexão sobre o papel dessas políticas no desenvolvimento (fortalecimento e/ou enfraquecimento) dos sistemas de educação superior na região. Especificamente, nos propomos a levantar, comparando com a realidade brasileira, alguns pontos relevantes da Colômbia em relação às múltiplas complexidades nas quais estão inscritos, na atualidade, os temas da acreditação e da avaliação. Destacamos apenas três: a) conceito de qualidade; b) forma de articulação das políticas face à crescente integração regional da educação superior; c) protagonistas das políticas.

A escolha pelos países Colômbia e Brasil deve-se à consolidação, desde a década de 90, de políticas educacionais voltadas aos temas da garantia e melhoria da qualidade da educação superior, além das características comuns presentes em seus sistemas educativos, notadamente marcados pela diversificação de instituições de educação superior (IES) e diferenciação de seus programas e cursos.

A palavra acreditação não existe em português. Recentemente, vem sendo utilizada no Brasil, e corresponde a um termo aproximado à palavra certificação. Em inglês (accreditation) ou espanhol (acreditación) equivale a um processo baseado em padrões e critérios objetivos para assegurar, vale dizer, garantir e reconhecer, a qualidade de uma instituição, curso ou programa de um dado sistema educativo. Comumente, o processo é acompanhado por agências externas à instituição ou ao país (RIACES, 2004). Enquanto a acreditação consiste em assegurar a qualidade, a avaliação compreende à melhoria desta, induzindo as instituições a um contínuo aperfeiçoamento. (DIAS SOBRINHO, 2005)

A opção pelo termo 'políticas' demonstra a nossa perspectiva em compreender o tema a partir da dinâmica da relação entre as IES, a sociedade e o Estado. Assim, políticas de acreditação e de avaliação referem-se ao conjunto de propostas (intenções) e ações (prática) de Estado e de Governo destinadas, respectivamente, a dar fé pública e a valorar as instituições de educação superior e os seus programas e cursos. Por sua vez, educação superior remete a um sentido mais amplo, considerando o termo no nível das políticas e sistemas e não no nível individual, isto é, das instituições em concreto.

Ham e Hill (1993, p.10-11) indicam sete variações para a compreensão das políticas sociais, entre as quais se situam as educacionais: (i) estudos do conteúdo (explicação da gênese e do desenvolvimento de uma política particular); (ii) 
estudos do processo de elaboração (estudo interessado em desvendar as variáveis que caracterizam as políticas específicas que influenciam uma determinada área ou assunto); (iii) estudos de resultados de políticas (explicam porque os níveis de gasto ou provisão de serviços variam entre diferentes áreas); (iv) estudos de avaliação ou estudo do impacto que as políticas têm sobre uma sociedade ou população; (v) informação para a elaboração de políticas (organização de dados a fim de auxiliar os tomadores de decisão); (vi) defesa de processos (aperfeiçoamento dos sistemas de elaboração de políticas) e (vii) defesa de políticas (atividade de pressão para fazer predominar idéias no processo de políticas).

Aqui, privilegiamos os estudos do processo de elaboração das políticas (ponto ii), pois permitem o entendimento das inúmeras características (traços significativos) que formam essas mesmas políticas, bem como a influência ativa delas para potencializar ou enfraquecer a configuração de determinado sistema educativo. Além disso, os estudos de elaboração das políticas permitem revelar a visão predominante de acreditação e avaliação à qual estão atrelados os atores envolvidos no processo.

Como premissa, consideramos que a educação superior na América Latina necessita buscar estratégias de formação e de produção com base em critérios nacionais e internacionais sem, porém, desconsiderar os processos produtivos e culturais locais e regionais (DIAS SOBRINHO, 2005). Como hipótese, sugerimos que os processos de garantia (acreditação) e melhoria (avaliação) da educação superior concebidos somente segundo os parâmetros dos países europeus acentuam assimetricamente o fenômeno da internacionalização da educação, não contribuindo de maneira significativa para o fortalecimento dos sistemas de educação, de ciência e de tecnologia nos países em desenvolvimento.

A partir dessa idéia geral, organizamos o texto em três partes. Na primeira, com base em autores que discutem o assunto, alguns dos quais publicaram os seus trabalhos na Revista da Avaliação da Educação Superior, apresentamos esquematicamente o processo que inspira e induz o desenvolvimento das políticas na América Latina, o chamado processo de Bolonha. Na segunda parte, respaldados na legislação e documentos oficiais, descrevemos as características do sistema nacional de acreditação da Colômbia, especialmente em relação às questões chave definidas no início desta introdução: conceito de qualidade, forma de integração na região e protagonistas da política.

Sabemos que são muitas as variáveis e as características que podem ser analisadas e discutidas em relação aos temas da acreditação e da avaliação. Todavia, devemos compreender que este artigo é parte de um estudo em desenvolvimento, portanto inacabado, não havendo a pretensão de fixar conclusões 
definitivas. Por tal razão, na terceira parte expomos algumas interfaces do Sistema Nacional de Acreditação da Colômbia com o do Brasil, apontando para algumas tendências futuras.

\section{Traços de contexto: o Processo de Bolonha}

Embora se constate, conforme atestam os estudos de Pires e Lemaitre (2008), que o processo de integração da educação superior na América Latina iniciouse antes mesmo do pacto de Bolonha, é a partir dele que a temática tomou maior impulso na região, especialmente no que diz respeito aos mecanismos de acreditação e de avaliação.

A experiência da Europa Ocidental colocou em evidência que o processo de integração da educação superior está intimamente relacionado com o desenvolvimento de padrões e critérios objetivos comparáveis e compatíveis entre si. Esses padrões e critérios encontram na acreditação e na avaliação as formas mais acabadas e complexas para alcançá-los. Enquanto a primeira forma busca assegurar a qualidade (garantindo os padrões de qualidade), a segunda procura estabelecer os parâmetros, permitindo a comparação e o aperfeiçoamento dos sistemas (critérios de qualidade). Assim, dificilmente discute-se na América Latina o papel da acreditação e da avaliação na configuração de políticas voltadas à integração da educação superior na região sem considerar a experiência e o processo que está se formando nos países desenvolvidos da Europa Ocidental, isto é, o processo de Bolonha.

Desde 1999, vem se desenvolvendo, em vários países europeus um conjunto amplo de transformações com a finalidade de promover a reforma dos sistemas de educação superior. Trata-se do chamado Processo de Bolonha ${ }^{2}$. O ponto de partida é um documento que marca o início desse processo, a Declaração de Bolonha (1999). Tanto a Declaração (o documento) quanto os seus desdobramentos (o processo) estabelecem uma gama de intenções e ações cujo horizonte é a integração dos sistemas de educação superior na Europa ${ }^{3}$.

A intenção de promover a integração dos sistemas de educação superior europeu teve iniciativa com a Sorbonne Joint Declaration (1998), através do documento Joint Declaration on Harmonisation of the Architecture of the

2 Segundo José Dias Sobrinho, é o "fenômeno mais expressivo que hoje ocorre na Europa e talvez mesmo no mundo todo" (2005, p. 170). Ver também, a respeito, Lima, Azevedo, Catani (2008).

3 Desde Paris, com a criação da Comunidade Européia do Carvão e do Aço - CECA (1951) e, depois, Roma, quando foram assinados em 1957 dois tratados que criaram a Comunidade Européia de Energia Atômica - CEEA e a Comunidade Econômica Européia - CEE, a Europa busca a sua integração econômica. De acordo com Azevedo (2006), a Declaração de Bolonha (1999) tem como objetivo a integração dos sistemas de educação superior, considerado um setor estratégico na formação da cultura e para o desenvolvimento europeu. 
European Higher Education System, assinada pelos Ministros da Educação da França, Alemanha, Itália e Reino Unido. Entretanto, as principais linhas e questões somente foram traçadas com a Declaração de Bolonha elaborada conjuntamente por 29 Ministros da Educação europeus, em Bolonha, no dia 19 de Junho de 1999. Daí a referência inicial deste estudo.

A partir dessa data, foi dado o prazo de dois anos para o compromisso de elaborar um documento onde inúmeras diretrizes fossem delimitadas para a construção do denominado 'Espaço Europeu de Ensino Superior'. Em maio de 2001, na cidade de Praga, o encontro realizado com os países signatários da Declaração de Bolonha, resultou na elaboração do documento Rumo a um Espaço Europeu de Ensino Superior. Este estabeleceu não só as características do futuro Espaço, mas também a data limite para a sua implantação, em 2010.

As declarações produzidas posteriormente, Salamanca (2001), Berlim (2003) e Bergen (2005), avançaram concretamente em relação às medidas a serem tomadas para o desenvolvimento desse Espaço. Em linhas gerais, elas convergem para homogeneização do processo de atribuição de diplomas de cursos de graduação e pós-graduação; a padronização dos valores a serem dados às carreiras e aos currículos acadêmicos; a implantação de uma estrutura única de formação contínua capaz de se estender facilmente a todos os Estados Membros da União Européia (UE); a promoção da mobilidade dos estudantes, professores, pesquisadores e uniformização dos critérios e instrumentos de acreditação ou certificação de qualidade para conferir mais transparência aos sistemas.

As diversas declarações mostram que, com o Processo de Bolonha, as políticas concernentes aos processos de garantia e melhoria da qualidade da educação superior na Europa deixaram de ser um mero apêndice na agenda dos governos para assumirem papel de destaque como política educacional ${ }^{4}$, isto é, como ação (inter) governamental na formulação das estratégias para reforma da educação superior.

Com efeito, mais que uma resposta à crise da educação superior ${ }^{5}$ em relação aos desafios trazidos pelo mundo da informação, atransformações culturais e dos avanços tecnológicos, o Processo de Bolonha vem implementando paulatinamente nos países membros da União Européia (UE) um sistema educacional

4 Morosini (2006, p. 96) afirma que "do ponto de vista do conhecimento a universidade sempre atuou numa perspectiva internacional, ou seja, por meio da cooperação internacional e intercâmbio entre professores e estudantes. O que difere do contexto atual é que esse modelo leva a IES assumi-lo como Política, isto é, a IES assume a internacionalização como política, planejando, implementando e executando sistematicamente em todos os níveis da organização".

5 Vários autores mencionam a crise que afeta a educação superior no mundo. Brunner (1994), por exemplo, apresenta a "crise de financiamento incremental", "crise de falta de regulação" e "crise por falta de avaliação". Goergen (2005) classifica em crise "conceitual", "contextual" e "textual". 
simétrico às novas demandas ou necessidades do mundo do trabalho, da economia e da sociedade da comunidade européia. Portanto, aquilo que denomina de Declaração de Bolonha e Processo de Bolonha formatam, respectivamente, intencional e operacionalmente, uma política de idéias, metas, programas, projetos e instrumentos bem delineados, com propósitos de reformar a educação superior européia num novo contexto, o da sociedade e economia do conhecimento, atendendo às demandas de formação de capital humano. Como diz o Relatório da Comissão Para um modelo europeu de ensino superior:

Não se pode ter a livre circulação de mercadorias, de capitais, de pessoas, de idéias [...], e manter uma situação em que não é mesmo possível comparar o valor dos diplomas expedidos pelas universidades dos países membros da União Européia [...] Não se pode ter a Europa do emprego sem a Europa da Educação. Sem uniformizar seus sistemas, os países da Europa deverão decidir a respeito de uma certa harmonização dos cursos e dos diplomas e definir um modelo europeu específico, nem burocrático nem submetido ao mercado. (ATTALI, 1998, p.18-19 apud Azevedo, 2006)

$\mathrm{O}$ trecho anterior ilustra as intenções colocadas em prática atualmente na Europa, pois correspondem às necessidades crescentes de (i) acesso (expansão das matrículas), (ii) formação condizente com os avanços da tecnologia (educação permanente com foco em competências e habilidades), (iii) flexibilidade (dos currículos), (iv) mobilidade (de professores e estudantes) e (v) atratividade (de cursos e profissões). Essas necessidades se acentuaram com o fenômeno da globalização. Graças às suas bases, calcadas em redes tecnológicas, a globalização impulsionou a transnacionalização dos mercados e dos processos de trabalho. Estes, por sua vez, induzem, no contexto do processo de Bolonha, a transnacionalização da cultura e da educação. Educação transnacional corresponde a todos os tipos de educação superior nos quais os aprendizes se encontram num país diferente daquele em que está baseada a instituição que a dispensa. (KNIGHT, 2004)

Conforme aponta Ianni (1999, p. 13),

Está em curso o novo surto de universalização do capitalismo, como modo de produção e processo civilizatório. O desenvolvimento do modo capitalista de produção, em forma extensiva e intensiva, adquire outro impulso, com base em novas tecnologias, criação de novos produtos, recriação da divisão internacional do trabalho e mundialização dos mercados. As forças produtivas básicas, compreendendo o capital, a tecnologia, a força de trabalho e a divisão transnacional 
do trabalho, ultrapassam fronteiras geográficas, históricas e culturais [...] A nova divisão transnacional do trabalho envolve a redistribuição das empresas, corporações e conglomerados por todo o mundo.

Esse movimento, descrito por Ianni, ainda em curso, incide sobre os sistemas educativos de modo a induzi-los à constante mudança seja, para oferecer um número maior de cursos, flexibilizar a forma de atendimento (presencial ou a distância) e grades curriculares ou para diferenciar e diversificar as funções da educação superior na sociedade. Trata-se, portanto, de acordo com Dias Sobrinho (2005), não de um remodelamento das instituições em seu plano individual, mas do sistema como um todo, readaptando a um novo tempo ou contexto iniciado desde a década de 70, qual seja, o desmantelamento do Estado-providência (Estado de bem-estar social) ${ }^{6}$.

Com efeito, o Processo de Bolonha, como materialização de um longo processo para reorganizar a educação superior na Europa, pretende criar as condições necessárias para a transição dos sistemas enquanto lugar de estratégia dos interesses dos Estados nacionais para o lugar de estratégia dos interesses do mundo globalizado, transnacionalizado, flexível e competitivo7.

Quais são os significados do Processo de Bolonha para o desenvolvimento das políticas para a educação superior? Como tem sido a postura e a posição dos diferentes atores sociais frente ao processo? Que concepções de qualidade são editadas por esse processo? São questões essenciais para a compreensão da temática, não somente do ponto de vista teórico, mas pelo grande impacto que têm sobre os sistemas de educação superior.

Várias complexidades permeiam o processo de Bolonha. Uma delas tem relação com a questão da garantia e melhoria da qualidade a partir de parâmetros estabelecidos internacionalmente, isto é, compatíveis e comparáveis em toda a Europa Ocidental. Um dos pontos-chave do processo de Bolonha, onde perpassam as suas metas, segundo Mora e Hortale (2004, p. 953), é a “exigência de estabelecer um sistema de garantia de qualidade eficaz e que possa a ser reconhecido pelo conjunto dos países europeus e de outros países”.

6 Afonso (2000, p. 99-100) afirma que “[...] na fase de expansão capitalista que se seguiu à II Guerra Mundial, o Estado - providência passou a ser a fórmula encontrada em muitos países para a gestão das contradições que vão tornar-se cada vez mais agudas como resultado, por um lado, da necessidade de o estado ter uma decisiva intervenção econômica e, por outro, de ter que criar condições para atender às novas e crescentes expectativas e necessidades sociais, muitas delas decorrentes do reconhecimento de direitos de cidadania como proteção social, o acesso aos cuidados de saúde e à educação”.

7 Para Dias Sobrinho (2005, p. 176) trata-se de "[...] uma reforma que seja capaz de superar as barreiras culturais, de idiomas, e modelos educativos desse nível e torná-lo mais eficiente e competitivo. Em resumo, trata-se de eliminar as barreiras que impedem a livre circulação de capitais, mercadorias, conhecimentos e pessoas, mais propriamente, dos profissionais". 
Em vários lugares no mundo observa-se a existência, em maior ou menor desenvolvimento, de formas para garantir e melhorar a qualidade das instituições e dos sistemas de educação superior. Essas formas dispostas de maneira articulada, sistematizada e formalmente estabelecidas num dado país são conhecidas como "mecanismo nacional de garantia pública de qualidade" (STUBRIN, 2005, p. 10). Dependendo do país os mecanismos de garantia de qualidade têm como base a avaliação ou acreditação, quando não a combinação dos dois mecanismos. Podem, ainda, ter como principal protagonista, isto é, interessado, o governo, as agências externas, as instituições e a sociedade. Não raro, o interesse pode partir de vários atores ao mesmo tempo ou apenas por parte de alguns deles. Isso irá depender do contexto social e histórico em que esses mecanismos emergem e, por conseguinte, do valor social atribuído a eles.

Na Europa, os processos de garantia e melhoria da qualidade foram implantados a partir dos anos 80. Nos anos 90, quase todos os países europeus estruturaram agências nacionais ou regionais para realizar a acreditação e avaliação de seus sistemas (MORA; HORTALE, 2004, p. 953-954). Enquanto os processos de acreditação atestam, isto é, dão fé pública sobre a qualidade de um determinado programa, curso ou instituição, os processos de avaliação os induzem constantemente à melhoria. Daí que esses processos são considerados fundamentais para o desenvolvimento da educação superior fazendo parte ativa da agenda da política educacional e da reforma institucional para formar a chamada ‘Área Européia de Educação Superior’ . A busca de integração econômica e cultural vem pressionando a construção de normas e regras mais ou menos comuns entre os países para a convergência também dos sistemas educativos e do reconhecimento de títulos e diplomas. (DIAS SOBRINHO, 2005, p. 147)

De fato, as diferentes declarações produzidas desde 1998 são taxativas em considerar que "é necessário apoiar medidas de acreditação em nível institucional, nacional e europeu, sendo imprescindível desenvolver critérios e metodologias comuns de acreditação” (COMMUBIQUÉ..., 2003) para promover a dimensão européia de garantia de qualidade e, fundamentalmente, o desenvolvimento do Sistema Europeu de Educação Superior.

Na América Latina, a partir dos anos 70, segundo os estudos do Instituto Internacional para la Educación Superior en América Latina y el Caribe IESALC (2006), surgiu primeiro a preocupação com a busca de qualidade, tornando-se um imperativo a partir da década de 90. A opção de boa parte dos países em desenhar políticas, leis e decretos educacionais que favorecessem direta ou indiretamente a atuação do setor privado para responder às novas demandas em educação superior - como a criação de diversos tipos de instituições 
universitárias e não universitárias -, acabou por gerar, entre outras situações, questionamentos sobre a legitimidade e qualidade da oferta educacional (PIRES, LEMAITRE, 2008). A avaliação, nesse contexto, ganhou presença e visibilidade na região. Porém, sempre mais relacionada ao caráter performático de sua aplicação do que aos aspectos formativos de sua função nas IES.

Somente mais tarde, durante o início deste século, foi introduzido o tema da acreditação como uma preocupação geral de toda a região latino-americana e Caribe. Essa preocupação, de acordo com Pires e Lemaitre (2008), foi conseqüência crescente da (i) importância da educação superior como componente essencial daquilo que se convencionou chamar de sociedade do conhecimento ou da era da informação e da (ii) crescente integração e integralização da educação superior no mundo e na região.

Contudo, como assinala Lopez Segrera (2006, p. 28), o processo de Bolonha, na América Latina, chegou como uma tendência e não como um modelo pronto e acabado. Segundo o autor, foi uma herança da cultura ocidental que, de certo modo, reuniu e levou os chefes de Estado e de Governo da União Européia e da América Latina e Caribe a declarar o seu interesse em desenvolver conjuntamente para criar, em analogia com o processo europeu, aquilo que em maio de 2002 a Declaração Política da Reunião denominou de Espaço Comum de Ensino Superior.

\section{Características do Sistema Nacional de Acreditação da Colômbia}

Antes de expormos as respostas encontradas para algumas das complexidades relacionadas à temática deste trabalho, faremos, ainda que sumariamente, uma contextualização do Sistema Nacional de Acreditação da Colômbia (SNA).

O SNA tem como principal foco a questão da garantia de qualidade, combinada com os processos de avaliação. Esse Sistema foi criado pela Lei 30 de 1992, segundo a qual "la Acreditación es un testimonio que da el Estado sobre la calidad de un programa o institución con base en un proceso previo de evaluación en el cual intervienen la institucion, las comunidades académicas y el Consejo Nacional de Acreditación.” (CNA, 1998)

O SNA é coordenado, em âmbito nacional, por meio do Conselho Nacional de Educação Superior (CESU), órgão público governamental ao qual compete, entre outras funções, desenvolver o Sistema Nacional de Acreditação e definir as funções e formas de integração do Conselho Nacional de Acreditação (CNA). O CNA, de natureza acadêmica, é um organismo também previsto pela referi- 
da Lei que orienta, fixa os critérios, define os procedimentos para a aplicação dos processos de acreditação, fiscaliza e dá fé pública sobre a qualidade dos programas e IES, recomendando ao Ministro da Educação Nacional acreditar ou não os programas e instituições.

A CESU conta também com outro organismo público vinculado ao Ministério da Educação Nacional (MEN) responsável pela execução das políticas, em especial pelo processo de avaliação, condição prévia e base para os processos de acreditação: o Instituto Colombiano para el Fomento de la Educación Superior (Icfes).

As instituições colombianas são bastante heterogêneas e se encontram estruturadas em Universidades (instituições que desenvolvem atividades como ensino, investigação e formação profissional), Instituições Técnicas Profissionais (instituições incumbidas de desenvolverem formação técnica ou instrumental) e Instituições Universitárias ou Escolas Tecnológicas (instituições que oferecem programas de formação acadêmica e profissional e disciplinas ou programas de especialização em determinada especialidade).

Os processos de acreditação ocorrem em nível dos programas (acreditação de programas) e em nível das instituições de educação superior (acreditação das IES). São duas as formas existentes para acreditar uma instituição ou programa no país: (i) Registro Qualificado - processo de Acreditação Prévia de Programas, de natureza obrigatória, com conotações de verificação e controle da qualidade da educação superior; (ii) Acreditação de Alta Qualidade, processo temporal e de adesão voluntária.

Os programas acadêmicos de graduação e de especialização ofertados pelas instituições de educação superior (IES) devem requerer, para poderem funcionar, o Registro Qualificado, outorgado pelo Ministro da Educação Nacional, tendo como parâmetro a recomendação da Comisión Nacional de Aseguramiento de la Calidad de la Educación Superior (CONACES). Considera-se que o Registro Qualificado define as condições mínimas de qualidade que um programa acadêmico deve ter para poder funcionar no sistema de educação superior. (CNA, 2009, p. 9)

A outra forma existente para acreditar uma IES ou programas é a chamada Acreditação de Alta Qualidade, que somente se realiza quando o programa acadêmico que deseja ser acreditado está em funcionamento pleno e tem várias promoções de estudantes egressos.

O processo de Acreditação de Alta Qualidade na Colômbia se outorga tanto para os programas de graduação (acreditação de programas) quanto para as 
instituições de educação superior (acreditação institucional). Porém, no país, a prioridade é dada aos programas de doutorado, tendo em vista o crescimento significativo destes programas e as políticas de fomento para o desenvolvimento dos mesmos. Segundo o documento para discussão Lineamientos para La Acreditación de Alta Calidad de Programas de Maestría y Doctorado (CNA, 2009, p. 6), em dezembro de 2008 constaram 92 programas de doutorado distribuídos em 22 universidades, dos quais 584 doutores obtiveram o título de doutor até dezembro do mencionado ano. Destes, 88 doutores titularam-se antes do ano de 2000 e 496, entre 2000 e 2007.

\subsection{Qual conceito de qualidade?}

Segundo o glossário elaborado pela Rede Iberoamericana para a Acreditação da Qualidade da Educação Superior (RIACES, 2004), a palavra qualidade corresponde ao grau em que um conjunto de traços diferenciadores inerentes à educação superior cumpre com uma necessidade ou expectativa estabelecida e convencionalmente aceita.

No caso das instituições ou programas, em concreto, diz respeito à capacidade ou propriedade para cumprir os padrões previamente estabelecidos por uma agência ou organismo externo de acreditação que, comumente, utiliza os processos avaliativos para valorar determinados aspectos das instituições e de seus programas, tais como, entre outros, docência, formação, produção, programas e cursos ofertados, aprendizagem, gestão e planejamento, condições de infraestrutura, pesquisa, interface com a comunidade, egressos.

Mas, como sabemos, da mesa forma que o conhecimento científico, o conceito de qualidade não é neutro. Carrega consigo certos referenciais contextuais, políticos, culturais e econômicos - por conseguinte, históricos e sociais. Por isso, não há um acordo universal sobre ele. Levantamento feito em vários países da América Latina, e divulgado pela IESALC/UNESCO (2006), aponta para diferentes perspectivas em relação ao significado do conceito de qualidade, entre elas, conjunção e integração da pertinência; eficiência e eficácia de uma instituição; processo contínuo e integrado; mérito pela excelência; direito do cidadão; relação entre produtos, processos e insumos; adequação entre o ser e dever ser da educação superior.

Com efeito, na prática permanece a discussão sobre o que está realmente em jogo nos processos que têm nesse conceito a sua base, como os processos de acreditação e avaliação da educação superior. Se a noção de qualidade está 
relacionada à pertinência (compromisso social) ou à noção de serviço (mercado); se a noção de qualidade tem como contexto a educação enquanto bem público nacional ou global ou é um bem negociável, sujeitos à lei de mercado; se os mecanismos de acreditação e avaliação da qualidade devem prestar informação ao mercado educacional ou devem funcionar como mecanismos de garantia e melhoria da educação como dever do Estado.

Na Colômbia, os processos de acreditação e avaliação da educação superior partem de critérios integrados e multidimensionais do conceito de qualidade, não havendo hierarquia entre estes critérios nem predileção de um sobre o outro: universalidade, integridade, equidade, idoneidade, responsabilidade, coerência, pertinência, transparência, eficácia e eficiência.

O conceito colombiano de qualidade de uma instituição ou programa tem como referência a síntese entre as características universais da educação superior - características genéricas que definem um ideal ou modelo estabelecido historicamente para esse tipo de instituição, e as características específicas próprias do projeto institucional, tais como missão, valores, objetivos e atuação na sociedade. Por esse ângulo, qualidade é o juízo (a percepção) obtido a partir de uma síntese na qual permite reconhecer as características (universais e específicas) de um programa acadêmico ou de uma instituição e a sua relativa distância entre o que ela é (modo de ser) e o que faz (modo de atuação). Qualidade, portanto, pressupõe um esforço permanente por parte das IES para cumprirem de forma responsável as exigências próprias de cada uma de suas funções básicas, investigação e ensino (características universais) e projeção social (características específicas do projeto local). (CNA, 2009)

\subsection{A articulação entre as políticas de acreditação e de avaliação face à crescente integração regional da educação}

A questão trabalhada no presente não é simples, tendo em vista as contradições inerentes entre as boas intenções expressas pelos governos e o rumo que elas de fato tomam no seu curso.

Como pano de fundo permanece a preocupação e a discussão acerca do papel dos mecanismos de acreditação e avaliação no fortalecimento dos sistemas educativos da América Latina e do Caribe, principalmente num cenário de assimetria em que ocorre a divisão internacional do conhecimento, a inovação tecnológica e a mercantilização da educação superior por meio do investimento das grandes corporações ou grupos privados na área educacional.

Uma das características do processo de Acreditação de Alta Qualidade das IES e de programas da Colômbia está relacionada, conforme o documento para 
discussão Lineamientos para La Acreditación de Alta Calidad de Programas de Maestría y Doctorado (CNA, 2009), com a política de internacionalização conduzida pelo CNA. São três os pilares que formatam essa política, quais sejam:

a) adoção da prática de avaliação externa internacional dos mestrados e doutorados com a participação de pares internacionais;

b) construção e desenvolvimento de mecanismos inovadores com a finalidade de realizar uma acreditação internacional a partir de "acreditações conjuntas" desencadeadas, por exemplo, no contexto do MERCOSUL, pelo Projeto MEXA - Mecanismo Experimental de Acreditação de Cursos;

c) criação de um sistema para troca de informações sobre os indicadores de qualidade dos doutorados nos países Iberoamericanos, possibilitando estabelecer metas de desempenho ("benchmarkinmg internacional”) com base em análises comparativas destes mesmos indicadores num mesmo campo da ciência. (CNA, 2009, p. 11)

Vale lembrar que a iniciativa que se desenvolve na Colômbia integra um contexto mais amplo que vem sendo construído em nível internacional pelos países da América Latina, Caribe e Iberoamericanos, no âmbito da RIACES internacionalização dos sistemas nacionais de acreditação.

\subsection{Quem são os protagonistas?}

Quem deve coordenar os processos de acreditação e avaliação? Segundo Catani e Oliveira (2000), a formatação das ações para remodelar o ensino superior no contexto de um debate transnacional, protagonizado por influentes organizações internacionais, é tema de investigação bem estabelecido, porém pouco conhecido. As agências externas e organismos supranacionais ocupam cada vez mais espaço no controle e gerenciamento dos padrões de qualidade para as instituições européias. A European Network for Quality Assurance in Higher Education (ENQA), por exemplo, derivada do European Pilot Project for Evaluating Quality in Higher Education, reúne os principais organismos de acreditação, governamentais e privados, de todos os países da Comunidade Européia, assim como outras agências como a Associação das Universidades Européias (EUA).

Na América Latina, a criação de agências, em sua maioria governamental, representou o estabelecimento de um marco regulatório entre a autonomia das 
universidades públicas (amparadas pela Constituição) e a liberdade de mercado das instituições privadas, na sua maior parte de pequeno porte e voltadas apenas para o ensino.

Dias Sobrinho (2007), em recente entrevista por escrito concedida à Global University Network for Innovation - GUNI, afirma que se trata de uma posição bastante complexa. De um lado porque as agências ou organismos internacionais não devem impor modelos rígidos de acreditação e, conseqüentemente, modelos de educação válidos universalmente para os diferentes países. Ao contrário, devem colaborar no fortalecimento de acordo entre os países, reforçando a autoridade dos Ministérios nacionais. De outro, porque os processos que visam garantir a qualidade educacional, geralmente estão atrelados às necessidades e prioridades de cada país, conforme os projetos políticos e à sua realidade social. Daí que as agências ou os organismos internacionais devem relevar os contextos locais e os projetos nacionais.

Na Colômbia, a coordenação dos processos de acreditação da qualidade da educação superior é de responsabilidade de uma Agência pública - Consejo Nacional de Acreditación (CNA). Os atores chave do processo de acreditação de alta qualidade de programas e instituições foram definidos pelo Decreto 2904, de 1995, da CESU. Posteriormente, o Decreto foi complementado por vários Acordos. A leitura desses diferentes acordos permite extrair algumas especificidades, a saber:

(1) Definição do CNA como organismo de natureza acadêmica - Acordo 01 de 2000 e Acordo 02 de 2005;

(2) Caráter voluntário e temporal dos processos de acreditação, diferenciando-se dos processos de inspeção e controle - Acordo 06 de 1995 e Acordo 02 de 2006;

(3) Definição dos espaços de temporalidade para a acreditação e renovação da acreditação de programas e instituições - Acordo 02 de 2006.

No que tange à condução dos processos, o modelo nacional de acreditação colombiano acentua na autoavaliação o compromisso de cada IES na busca de qualidade. Nesse aspecto, o modelo contém diretrizes nas quais a própria universidade deve desenvolver o modelo específico de avaliação que utiliza, valendo-se da participação dos alunos e dos professores para avaliar os aspectos relacionados ao ensino e à aprendizagem. Põe em relevo a avaliação externa ou por pares designados pelo CNA, colocando a comunidade acadêmica como 
referência reconhecida e legítima para apreciar as instituições e programas de um determinado campo específico. Por fim, deposita no Estado, por meio do CNA, a quem corresponde a função de presidir e recomendar a acreditação, e por meio do MEN, a quem corresponde o ato de proferir a acreditação, a função de garantir a qualidade do trabalho desenvolvido pelas IES, dando fé pública sobre os "serviços" educacionais prestados por elas. (CESU, 1995; CNA, 2006 apud CNA 2009, p. 15)

\section{Acreditação e avaliação: interfaces entre a Colômbia e o Brasil}

Nesta seção apresentamos, tendo como base as explicações discutidas nas seções anteriores, alguns pontos do Sistema Nacional de Acreditação da Colômbia (SNA) que podem ser comparados com a realidade da educação superior brasileira.

No Brasil, a formação das políticas e dos processos para tratar da questão da qualidade na educação superior teve quase sempre a indução dos órgãos e das agências governamentais. Essa formação, à luz das contradições ${ }^{8}$, desde a sua entrada na lista de prioridades e metas da agenda governamental (construção) até a sua consolidação como pilar das políticas educacionais para orientar as modificações no sistema da educação superior brasileira (implementação) iniciou-se justamente pela avaliação. Primeiro, a avaliação da pós-graduação realizada, desde a década de 70, pela Coordenação de Aperfeiçoamento de Pessoal de Nível Superior (CAPES). Mais tarde, durante as décadas de 80 e 90, avaliação da graduação, realizada pelo Instituto Nacional de Estudos e Pesquisas Educacionais (INEP).

Na atualidade, na aplicação da avaliação da educação superior trabalham de forma integrada o Ministério da Educação (MEC), por meio da Secretaria de Ensino Superior (SESu), responsável pela regulação do sistema, o INEP, encarregado das avaliações da Graduação, o Conselho Nacional de Avaliação da Educação Superior (CONAES), responsável pelas diretrizes da avaliação, a CAPES, órgão responsável pelas avaliações da Pós-Graduação e Conselho Nacional de Educação (CNE), através da Câmara de Educação Superior.

8 Almeida Júnior (2005) mostra que a formação das políticas de avaliação para a graduação no Brasil não ocorreu de modo linear, caracterizando-se, inicialmente, nos anos 80 , pela experiência e participação predominante de atores acadêmicos e pela configuração de um modelo institucional cuja proposta, de adesão voluntária, tinha como referencial a universidade pública, como o Programa de Avaliação Institucional das Universidades Brasileiras (PAIUB). Posteriormente, na fase de consolidação, nos anos 90, predominou a visão e a participação de atores representantes das esferas governamentais, cujo modelo valorizava a avaliação de desempenho na aprendizagem e de resultados quantitativos. 
A utilização do termo acreditação no país é recente, tendo em vista a configuração de dois contextos, o da internacionalização da educação superior e as ações conjuntas para fortalecer as relações entre as nações e os blocos de países, como por exemplo, no âmbito do MERCOSUL, o Acordo sobre a Criação e a Implementação de um Sistema de Credenciamento de Cursos de Graduação para o Reconhecimento Regional da Qualidade Acadêmica dos Respectivos Diplomas no MERCOSUL e Estados Associados, (cidade de San Miguel de Tucumán, República Argentina, 30 de junho de 2008).

No país, como demonstra Leite (2002), não se desenharam os processos de acreditação. Entretanto, mesmo sem o uso do termo, "confirma-se a idéia de que as IES credenciadas e recredenciadas merecem confiança, pois foram alvo, por parte do governo, sob o olhar dos pares acadêmicos, especialistas, de um cuidadoso e escalonado processo de supervisão e avaliação, legalmente instituído, para assegurar uma certa uniformidade e qualidade mínima ao sistema público e privado" (p. 102).

Nos textos e documentos oficiais são utilizados os termos regulação, supervisão e avaliação. "Regulação" designa o conjunto de processos e atos para a autorização do funcionamento, reconhecimento de programas e credenciamento das instituições. O termo "supervisão" se refere à garantia de conformidade da oferta com a legislação; “a avaliação”, por sua vez, é um processo de melhoria e base para a regulação e supervisão. A expressão "avaliação da educação superior” corresponde tanto às modalidades de avaliação para a melhoria quanto à acreditação para garantir a qualidade. (DIAS SOBRINHO, 2007)

A palavra "qualidade", expressa na Lei no 10.861 de 14 de abril de 2004, que instituiu o Sistema Nacional de Avaliação da Educação Superior (SINAES), está atrelada à noção de eficácia institucional e efetividade acadêmica e social, especialmente a promoção do aprofundamento dos compromissos e responsabilidades sociais das instituições de educação superior, por meio da valorização de sua missão pública, da promoção dos valores democráticos, do respeito à diferença e à diversidade, da afirmação da autonomia e da identidade institucional (Art. $1^{\circ}, \S 1^{\circ}$ ).

Em suma, levando-se em conta que no Brasil a estrutura organizacional das instituições é bastante diversificada ${ }^{9}$, englobando instituições universitárias e não universitárias, coexistem duas formas para a avaliação da educação

9 De acordo com o Decreto Federal n 5773 de 9/5/2006 o sistema federal de ensino superior brasileiro compreende as instituições federais de educação superior, as instituições de educação superior criadas e mantidas pela iniciativa privada e os órgãos federais de educação superior. Essas instituições representam formas distintas de organização acadêmica (universidades, centros universitários e faculdades). 
superior, uma aplicada aos programas da pós-graduação, conduzida pela CAPES, e a outra no âmbito da graduação, conduzida pelo INEP.

A avaliação da graduação foca, segundo a Lei que instituiu o SINAES em 2004, as instituições, cursos e estudantes por meio de três etapas: (i) Avaliação das Instituições de Educação Superior (AVALIES), compreendendo a avaliação externa, realizada por especialistas designados pelo MEC e a avaliação interna, de responsabilidade das instituições, conduzida pelas Comissões Próprias de Avaliação (CPA); (ii) Avaliação dos Cursos de Graduação (ACG), realizada por especialistas de área designados pelo INEP; (iii) Exame Nacional de Avaliação do Desempenho dos Estudantes (ENADE), aplicado por amostragem aos estudantes do primeiro e último ano do curso de graduação.

Até recentemente, esse sistema vem se caracterizando pela integração dos diversos instrumentos, momentos e espaços com base em uma concepção global; articulação entre os processos de regulação e avaliação; coerência da concepção geral da avaliação com os objetivos e a política da educação superior; envolvimento de todas as IES do país; valorização do regime de colaboração entre os sistemas federal e estadual; combinação dos aspectos gerais com o respeito à identidade e diversidade institucionais.

A avaliação dos programas de pós-graduação, de responsabilidade da CAPES, consiste na realização do acompanhamento anual e da avaliação trienal do desempenho de todos os programas e cursos que integram o Sistema Nacional de Pós-Graduação (SNPG). Os resultados desse processo, expressos pela atribuição de uma nota na escala de "1" a "7", fundamentam a deliberação CNE/ MEC sobre quais cursos obterão a renovação de reconhecimento, a vigorar no triênio subseqüente.

A avaliação das propostas de cursos novos de pós-graduação é parte do processo estabelecido para a admissão de novos programas e cursos ao SNPG. Assim a CAPES, ao avaliar as propostas de cursos novos, verifica a qualidade das propostas observando se as mesmas correspondem ao padrão de qualidade requerido para a formação nesse nível. Em seguida, encaminha os resultados do processo, em consonância com a legislação vigente, para fundamentar a deliberação do CNE/MEC sobre o reconhecimento dos cursos e sua incorporação ao SNPG.

Na perspectiva da CAPES, de acordo com Ribeiro (2006), um projeto sobre os modelos de acreditação e avaliação da pós-graduação na América Latina e Caribe devem avançar em duas etapas. Numa primeira, na construção de um modelo que permita o reconhecimento dos dados necessários para a avaliação 
dos programas de mestrado e doutorado, de forma que os diferentes sistemas nacionais possam verificar e medir a qualidade dos cursos dos países com os quais desejam construir alianças. Numa segunda, a construção por adesão de um sistema supranacional de avaliação que estabeleça os critérios principais para medir a qualidade dos programas nos diferentes países.

Face ao exposto até aqui, podemos extrair, então, alguns pontos de simetria relevantes. De modo geral ambos os casos apresentam em comum:

a) Processos mistos e complexos, combinando a acreditação e a avaliação com os processos de regulação e controle;

b) Uso do mecanismo de avaliação como base para a acreditação;

c) Mecanismos diferenciados para a graduação e a pós-graduação;

d) Centralidade da coordenação, supervisão e aplicação dos mecanismos de acreditação e avaliação em agências governamentais;

e) Tendência em dar maior visibilidade e valor à avaliação externa no desenvolvimento do processo;

f) Independência maior das agências que atuam na pós-graduação frente aos governos e instituições;

g) Articulação frágil entre os mecanismos implantados na pós-graduação com os da graduação;

h) Tendência em articular os interesses nacionais com os padrões e critérios estabelecidos em nível internacional e regional;

i) Relação direta entre padronização e harmonização da educação superior com a busca pela garantia e melhoria da qualidade da educação superior;

j) Ênfase na qualidade como conceito de eficácia social e acadêmica;

k) Participação da comunidade acadêmica como referência reconhecida e legítima para apreciar as instituições e programas de um determinado campo específico;

l) Preocupação em ampliar a mobilidade estudantil e docente num quadro de qualidade educativa e científica;

m) Evidência e constância da temática da responsabilidade social na educação superior. 


\section{Considerações finais}

No decorrer das seções apresentadas procuramos expor algumas das características das políticas de acreditação e de avaliação da qualidade educação superior da Colômbia. Mais especificamente, procuramos compreender o Sistema Nacional de Acreditação colombiano no contexto de três grandes complexidades nas quais estão inscritas hoje a temática, quais sejam, conceito de qualidade, preocupação com a integração internacional e regional e os protagonistas da política. Destacamos, ainda, vários pontos de convergência com o contexto e a trajetória dos processos desenvolvidos na educação superior brasileira.

De modo geral, esse empreendimento foi bastante útil para contribuir com a reflexão sobre o papel dos processos de acreditação e avaliação no fortalecimento dos sistemas educativos dos países da América Latina. Ao que tudo indica, segundo os estudos parcialmente construídos aqui, os mecanismos de acreditação e avaliação estão na lista de prioridades da agenda governamental e acadêmica tanto na Colômbia quanto no Brasil. Nesse quadro, eles representam o esforço de cooperação internacional na região, porém com dupla finalidade e não isento de contradições: de um lado, para defender os interesses nacionais, dando ênfase à educação superior como bem público sujeito às ações e estratégias do Estado e não do mercado e, de outro, para ampliar a mobilidade estudantil e docente num quadro crescente de mudanças sociais, econômicas e culturais, garantindo e assegurando a qualidade da formação educacional e científica das pessoas.

\section{Referências}

AFONSO, Almerindo Janela. Avaliação educacional: emancipação e regulação. São Paulo: Cortez, 2000.

ALMEIDA JÚNIOR, Vicente de Paula. Uma análise do processo de formação das políticas de avaliação da educação superior no Brasil. Avaliação, Campinas; Sorocaba, v. 10, n. 1, mar. 2005.

ANTUNES, Fátima. O espaço europeu de ensino superior para uma nova ordem educacional? Educação Temática Digital, Dossiês, Campinas, v. 9, n. esp., dez. 2007. 
AZEVEDO, Mário Luiz Neves de. A integração dos sistemas de educação superior na Europa: de Roma a Bolonha ou da integração econômica à integração acadêmica. In: SILVA JUNIOR, João dos Reis; OLIVEIRA, João Ferreira de; MANCEBO, Deise (Orgs.). Reforma Universitária: dimensões e perspectivas. Campinas: Alínea/Anped, 2006, v. 1, p. 171-186.

BERLIN COMMUNIQUÉ. Berlim, 19 set. 2003. Disponível em: <http:// www.bologna-berlin2003.de/pdf/Communique1.pdf >. Acesso em: 15 out. 2007.

BRUNNER, José J. Estado y educación superior en América Latina. In: NEAVE, Guy; VAN VUGHT, Frans A. Prometeo encadenado: Estado y educación superior en Europa. Barcelona, Espanha: Gedisa, 1994.

CATANI, A. M.; OLIVEIRA, J. F. de; DOURADO, F. A política de avaliação da educação superior no Brasil em questão. In: DIAS SOBRINHO, José; RISTOFF, Dilvo. (Orgs.). Avaliação democrática: para uma universidade cidadã. Florianópolis: Insular, 2002.

CATANI, A. M.; OLIVEIRA, J. F. de; A reestruturação da educação superior no debate internacional: a padronização das políticas de diversificação e diferenciação. Revista Portuguesa de Educação, Braga, Portugal, v. 13, n. 2, p. 29-52, 2000.

CNA - CONSEJO NACIONAL DE ACREDITACIÓN. Criterios y procedimientos para la verificación de estandares de calidad de programas académicos de pregrado en ingenieria. Colômbia, Bogotá, 2001. Disponível em: <www.cna.gov.co>. Acesso em: 12 dez. 2008 CNA - CONSEJO NACIONAL DE ACREDITACIÓN. Criterios y procedimientos para la acreditación previa de los programas acadêmicos de pregrado y de especialización en educación. Colômbia, Bogotá, 1998. Disponível em: <www.cna.gov.co>. Acesso em: 12 dez. 2008.

CNA - CONSEJO NACIONAL DE ACREDITACIÓN. Lineamientos para la acreditación de alta calidad de programas de maestría y doctorado. Colômbia, Bogotá, 2009. Disponível em: <www.cna.gov.co>. Acesso em: 12 mar. 2009.

COMMUNIQUÉ OF THE CONFERENCE OF EUROPEAN MINISTERS RESPONSIBLE FOR HIGHER EDUCATION. Bergen, 19-20 may, 2005. p. 01-06. Disponível em: <http://europa.eu.int/comm/education/bergen.pdf>. Acesso em: 15 out. 2007. 
COMMUNIQUÉ OF THE MEETING OF EUROPEAN MINISTERS IN CHARGE OF HIGHER EDUCATION. Prague, may 19 th 2001. Disponível em: <http://europa.eu.int/comm/education/prague.pdf $>$. Acesso em: 15 out 2007.

\section{DIAS SOBRINHO, J. Dilemas da educação superior no mundo}

globalizado: sociedade do conhecimento ou economia do conhecimento? São Paulo: Casa do Psicólogo, 2005.

DIAS SOBRINHO, J. Acreditación de la educación superior en América Latina y el caribe. In: LA EDUCACIÓN SUPERIOR EN EL MUNDO 2007. Global university network for innovation, Barcelona, 2007. p. 282-294. GOERGEN, Pedro. Prefácio. In: DIAS SOBRINHO, J. Dilemas da educação superior no mundo globalizado: sociedade do conhecimento ou economia do conhecimento? São Paulo: Casa do Psicólogo, 2005. p.11-21. HAM, C.; HILL, M. The policy process in the modern capitalist state. London: Harvester Wheatsheaf, 1993.

IANNI, Octavio. A era do globalismo. Rio de Janeiro: Civilização Brasileira, 1999.

IESALC - INSTITUTO INTERNACIONAL PARA LA EDUCACIÓN SUPERIOR EM AMÉRICA LATINA Y EL CARIBE, 2006. Disponível em: $<$ http://www.iesalc.unesco.org.ve/general/Boletin-EvalyAcred.htm>. Acesso em: 19 jan. 2007.

\section{JOINT DECLARATION ON HARMONISATION OF THE} ARCHITECTURE OF THE EUROPEAN HIGHER EDUCATION SYSTEM. Paris, 25 may, 1998. p. 02-03. Disponível em: <http://eees. universia.pt/associacoes.jsp>. Acesso em: 23 nov. 2008 KNIGHT, Jane. Comercialización de servicios de educación superior: implicaciones del AGCS. In: GARCÍA-GUADILLA, Carmen (Org.). El difícil equilibrio: la educación superior como bien público y comercio de servicios. Universidad de Castilla-La Mancha, Cuenca, Espanha, 2004. LEITE, Denise. Sistemas de avaliação das instituições de ensino superior no Brasil. In: INSTITUTO INTERNACIONAL PARA A EDUCAÇÃO SUPERIOR NA AMÉRICA LATINA E NO CARIBE, IESALC/UNESCO.

A educação superior no Brasil, Caracas, 2002.

LIMA, Licidio C.; AZEVEDO, Mário L. Neves de; CATANI, Afrânio M. O processo de Bolonha, a avaliação da educação superior e algumas considerações sobre a Universidade Nova. Avaliação, Campinas; Sorocaba, v. 13, n. 1, p. 07-36, mar. 2008. 
LOPEZ SEGRERA, Francisco. América Latina y el Caribe: principales tendencias de la educación superior. Avaliação, Campinas; Sorocaba, v. 11, n. 3, p. 09-36, set. 2006.

MESSAGE FROM THE SALAMANCA CONVENTION OF EUROPEAN HIGHER EDUCATION INSTITUTIONS. Salamanca, 29-30 march, 2001. p. 01-04. Disponível em: <http://eua.ini-graz.at/Salamanca_Message.pdf > Acesso em: 10 set. 2007

MORA, José-Ginés; HORTALE, Virgínia Alonso. Tendências das reformas da educação superior no contexto do processo de Bolonha. Educação e Sociedade, Campinas, v. 25, n. 88, p. 937-960, out. 2004. Disponível em: $<$ http://www.cedes.unicamp.br>. Acesso em: 06 fev. 2007.

MOROSINI, Marília. Internacionalização da educação superior: um modelo em construção? In: RISTOFF, Dilvo; SEVEGNANI, Palmira (Orgs.).

Modelos institucionais de educação superior. Brasília, DF, Ministério da Educação. 2006. p. 93-118.

PIRES, Sueli; LEMAITRE, Maria José. Sistemas de acreditación y evaluación de la educación superior en América Latina y el Caribe. In: CONFERENCIA REGIONAL DE EDUCACIÓN SUPERIOR 2008. Disponível em: $<$ http://www.cres2008.org>. Acesso em: 27 out. 2008. REPÚBLICA DA COLÔMBIA. Ley 30 de Diciembre 28 de 1992. In: RIACES. Glosario Internacional RIACES de Evaluación de la Calidad y Acreditación. Documento MADRID 2004, Rede Iberoamericana para la Acreditación de la Calidad de Educación Superior. Madrid, 2004.

RIACES. RED IBEROAMERICANA PARA LA ACREDITACIÓN DE LA CALIDAD DE LA EDUCACIÓN SUPERIOR. Glosario 2004. Disponível em: <http://www.riaces.net/glosarioc.html>. Acesso em: 5 abr. 2009.

RIBEIRO, Renato J. Modelos de Acreditación y Evaluación de los Sistemas de Postgrados en América Latina y el Caribe. In: IESALC - INSTITUTO INTERNACIONAL PARA LA EDUCACIÓN SUPERIOR EM AMÉRICA LATINA Y EL CARIBE, 2006. Disponível em: <http://www.iesalc.unesco. org.ve/general/Boletin-EvalyAcred.htm>. Acesso em: 19 jan. 2007.

STUBRIN, Adolfo. Los mecanismos nacionales de garantía pública de calidad en el marco de la internacionalización de la educación superior. Avaliação, Campinas; Sorocaba, v. 10, n. 4, p. 09-22, dez. 2005. 